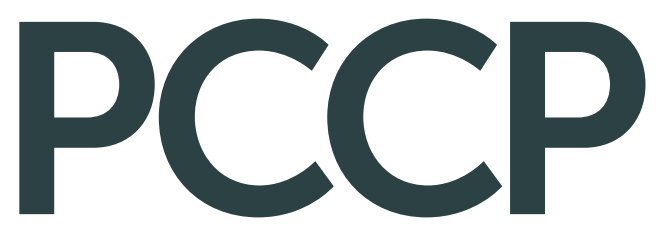

Accepted Manuscript

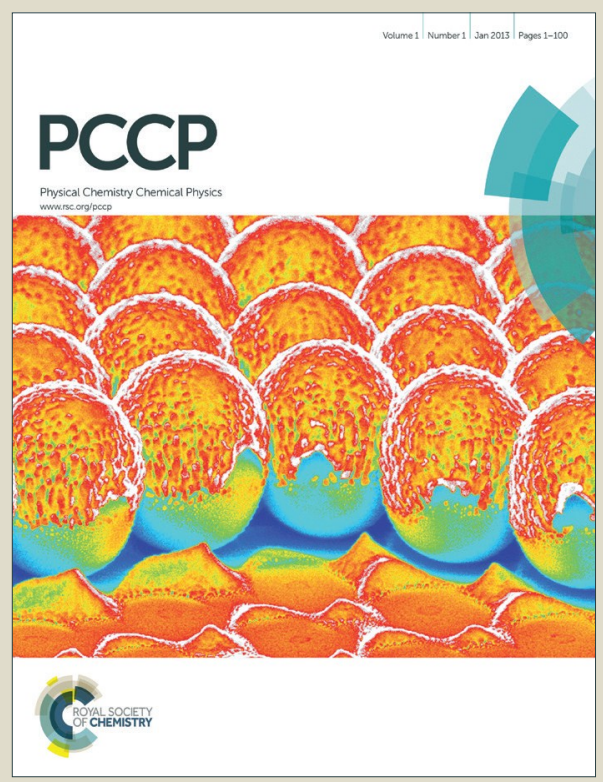

This is an Accepted Manuscript, which has been through the Royal Society of Chemistry peer review process and has been accepted for publication.

Accepted Manuscripts are published online shortly after acceptance, before technical editing, formatting and proof reading. Using this free service, authors can make their results available to the community, in citable form, before we publish the edited article. We will replace this Accepted Manuscript with the edited and formatted Advance Article as soon as it is available.

You can find more information about Accepted Manuscripts in the Information for Authors.

Please note that technical editing may introduce minor changes to the text and/or graphics, which may alter content. The journal's standard Terms \& Conditions and the Ethical guidelines still apply. In no event shall the Royal Society of Chemistry be held responsible for any errors or omissions in this Accepted Manuscript or any consequences arising from the use of any information it contains. 


\section{Shock Wave Study and Theoretical Modeling of the Thermal Decomposition of $c-C_{4} F_{8}$}

C. J. Cobos ${ }^{\mathrm{a}}$, K. Hintzer ${ }^{\mathrm{b}}$, L. Sölter ${ }^{\mathrm{c}}$, E. Tellbach ${ }^{\mathrm{c}}$, A. Thaler ${ }^{\mathrm{b}}$, and J. Troe ${ }^{\mathrm{c}, \mathrm{d}, *}$

Submitted August 2015

Revised October 2015

to be published in Phys. Chem. Chem. Phys.

a) INIFTA, Facultad de Ciencias Exactas, Universidad Nacional de La Plata, Argentina

b) Dyneon GmbH, Gendorf, D-84508 Burgkirchen, Germany

c) Institut für Physikalische Chemie, Universität Göttingen, Tammannstr. 6, D-37077 Göttingen, Germany

d) Max-Planck-Institut für biophysikalische Chemie, Am Fassberg 11, D-37077 Göttingen, Germany

*) jtroe $@ g$ gwdg.de 


\begin{abstract}
The thermal dissociation of octafluorocyclobutane, $\mathrm{c}-\mathrm{C}_{4} \mathrm{~F}_{8}$, was studied in shock waves over the range $1150-2300 \mathrm{~K}$ by recording UV absorption signals of $\mathrm{CF}_{2}$. It was found that the primary reaction nearly exclusively produces $2 \mathrm{C}_{2} \mathrm{~F}_{4}$ which afterwards decomposes to $4 \mathrm{CF}_{2}$. A primary reaction leading to $\mathrm{CF}_{2}+\mathrm{C}_{3} \mathrm{~F}_{6}$ is not detected (an upper limit to the yield of the latter channel was found to be about 10 percent). The temperature range of earlier single pulse shock wave experiments was extended.The reaction was shown to be close to its high pressure limit. Combining high and low temperature results leads to a rate constant for the primary dissociation of $k_{1}=10^{15.97} \exp \left(-310.5 \mathrm{~kJ} \mathrm{~mol}^{-1} / \mathrm{RT}\right)$ $\mathrm{s}^{-1}$ in the range $630-1330 \mathrm{~K}$, over which $k_{1}$ varies over nearly 14 orders of magnitude. Calculations of the energetics of the reaction pathway and the rate constants support the conclusions from the experiments. Also they shed light on the role of the 1,4-biradical $\mathrm{CF}_{2} \mathrm{CF}_{2} \mathrm{CF}_{2} \mathrm{CF}_{2}$ as an intermediate of the reaction.
\end{abstract}




\section{Introduction}

Octafluorocyclobutane, $\mathrm{c}-\mathrm{C}_{4} \mathrm{~F}_{8}$, is an important intermediate in the thermolysis of tetrafluoroethene, $\mathrm{C}_{2} \mathrm{~F}_{4}$, thus constituting evidence for a chain elongation during this process ${ }^{1,2}$. Besides c- $\mathrm{C}_{4} \mathrm{~F}_{8}$, substantial quantities of $\mathrm{CF}_{3} \mathrm{CF}=\mathrm{CF}_{2}, \mathrm{C}_{3} \mathrm{~F}_{6}$, and $\mathrm{CF}_{2}=\mathrm{C}\left(\mathrm{CF}_{3}\right)_{2}, \quad \mathrm{i}-\mathrm{C}_{4} \mathrm{~F}_{8}$, have been observed earlier in this interesting reaction system. While it is well established that singlet difluorocarbene, $\mathrm{CF}_{2}$, plays an important role in the kinetics, it remains unclear whether $\mathrm{C}_{3} \mathrm{~F}_{6}$ is a primary product of the decomposition of $\mathrm{c}-\mathrm{C}_{4} \mathrm{~F}_{8}$ or whether it arises from secondary interaction of $\mathrm{CF}_{2}$ with $\mathrm{C}_{2} \mathrm{~F}_{4}$. A direct observation of $\mathrm{CF}_{2}$ formation during the thermal dissociation of $\mathrm{c}-\mathrm{C}_{4} \mathrm{~F}_{8}$ may answer this question. This is the object of the present study. As $\mathrm{CF}_{2}$ plays an important role in many technical applications, such as plasma etching with fluorocarbons, synthesis of fluorocarbon polymers and their incineration, understanding its reactions is of practical and fundamental interest as well.

In previous work we have investigated the temperature dependence of the UV absorption spectrum of $\mathrm{CF}_{2}$ and carefully calibrated its absorption coefficient ${ }^{3}$. This gave us the opportunity to monitor the primary steps of the dissociations of $\mathrm{C}_{2} \mathrm{~F}_{4}{ }^{3}, \mathrm{C}_{3} \mathrm{~F}_{6}{ }^{4}$, and $\mathrm{c}_{-} \mathrm{C}_{3} \mathrm{~F}_{6}{ }^{5}$ with respect to their rates and branching pathways. In continuation of these studies we now try to distinguish between the two primary dissociation pathways of $\mathrm{c}-\mathrm{C}_{4} \mathrm{~F}_{8}$,

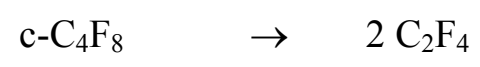

and

$\mathrm{c}-\mathrm{C}_{4} \mathrm{~F}_{8} \quad \rightarrow \quad \mathrm{CF}_{2}+\mathrm{C}_{3} \mathrm{~F}_{6}$ 
where reaction (1) would be followed by

$\mathrm{C}_{2} \mathrm{~F}_{4} \quad \rightarrow \quad 2 \mathrm{CF}_{2}$

Beside reaction (2), $\mathrm{C}_{3} \mathrm{~F}_{6}$ could also be formed by bimolecular processes like

$\mathrm{CF}_{2}+\mathrm{C}_{2} \mathrm{~F}_{4} \quad \rightarrow \quad \mathrm{C}_{3} \mathrm{~F}_{6}$

While all previous studies ${ }^{6-13}$ used end product analysis and, in consequence, no direct observation of $\mathrm{CF}_{2}$ was possible, it was difficult to unambigously identify the origin of $\mathrm{C}_{3} \mathrm{~F}_{6}$. By studying the reaction in shock waves, one has the added benefit that wall reactions are excluded. The latter played some role in earlier low temperature experiments using static reactors (see the discussion by Poutsma ${ }^{1}$ ). They were avoided in previous shock wave experiments ${ }^{11-13}$ which used the single pulse technique. However, there were considerable discrepancies in the results of these studies ${ }^{12,13}$ which were attributed to shock wave nonidealities ${ }^{13}$. Accounting for these, satisfactory consistency of the rate constants from static reactor studies ( e.g., experiments by Butler ${ }^{6}$ over the range 633 - $833 \mathrm{~K}$ ) and from singlepulse shock waves (experiments by Simmie et al ${ }^{13}$ over the range $1100-1265 \mathrm{~K}$ ) was obtained.

Different opinions were expressed about the branching between reactions (1) and (2). Nearly equal values of the rate constants $k_{1}$ and $k_{2}$ at $1200 \mathrm{~K}$ were suggested by Bauer and 
Javanovic $^{2} . k_{2}<<0.1 k_{1}$ was on the other hand concluded from the end product analysis of the single pulse shock wave experiments of Simmie et $\mathrm{al}^{13}$. As a consequence of these opposing conclusions, the $\mathrm{c}-\mathrm{C}_{4} \mathrm{~F}_{8}$ decomposition can so far not serve as a "chemical thermometer" for high temperature reactors, such as proposed by Bauer and Javanovic ${ }^{2}$. By observing $\mathrm{CF}_{2}$ directly in the reaction, the present study allows one to settle the question of the branching between reactions (1) and (2).

One could verify the simplicity of the mechanism of reaction (1) followed by reaction (3) in various ways. As long as conditions are employed where $k_{1} \approx k_{3}, \mathrm{CF}_{2}$ appearance should be accelerated with time and governed both by $k_{1}$ and $k_{3}$. When $k_{1}>>k_{3}, \mathrm{CF}_{2}$ appearance should be immediate and completely governed by reaction (3). Studying the reaction at the same temperature in reflected waves (with $k_{1} \approx k_{3}$ ) and in incident waves (with $k_{1}>>k_{3}$ because of the falloff of $k_{3}$ at lower pressures ${ }^{3}$ ), the two pathways of the kinetics should become distinguishable in the present type of experiments.

Besides experimental work quantum-chemical calculations may help to clarify the energetics and structures of possible intermediates of reactions (1) and (2). With these results dissociation rate constants could be calculated by applying unimolecular rate theory. An important aspect here is the contribution of a pathway involving a 1,4-biradical $\mathrm{CF}_{2} \mathrm{CF}_{2} \mathrm{CF}_{2} \mathrm{CF}_{2}$, in competition to more direct pathways. The analogy to the mechanism of the decomposition of $\mathrm{c}-\mathrm{C}_{3} \mathrm{~F}_{6}$, involving an intermediate 1,3 -biradical $\mathrm{CF}_{2} \mathrm{CF}_{2} \mathrm{CF}_{2}$, is obvious and also of interest ${ }^{5}$. Our present quantum-chemical calculations update and extend earlier work from Yokoyama et $\mathrm{al}^{14}$. While the precision of our rate constant calculations will still 
leave something to be desired, the comparison of experiment and theory nevertheless should shed some light on the question of the relative importance of reactions (1) and (2).

\section{Experimental Technique and Results}

As described in detail in our earlier work ${ }^{3-5}$, we recorded UV absorption signals of $\mathrm{CF}_{2}$ at 248 $\mathrm{nm}$ during the dissociation of $\mathrm{c}-\mathrm{C}_{4} \mathrm{~F}_{8}$ behind incident and reflected shock waves. In brief, we used an aluminum shock tube of $10 \mathrm{~cm}$ inner diameter with a low pressure section of $4.15 \mathrm{~m}$ and a high pressure section of $2.80 \mathrm{~m}$ length. The driver gas was hydrogen at pressures between 2 and 15 bar. The light source for UV absorption measurements was a Xenon high pressure arc lamp (Osram XBO $150 \mathrm{~W}$ ); wavelengths were selected by a prism monochromator (Zeiss, MQ3) and signals were recorded with a photomultiplier (Hamamatsu E2420) transient recorder arrangement. Mixtures of the reactant and the bath gas were prepared in large mixing vessels before the experiments. The initial concentrations of $\mathrm{c}-\mathrm{C}_{4} \mathrm{~F}_{8}$ (purity $>99 \%$, from abcr) in Ar (purity $>99,9999 \%$, from Air Liquide) were varied between 80 and 1000 ppm. Temperatures between 1150 and $2300 \mathrm{~K}$ were applied for $\mathrm{CF}_{2}$ yield measurements and $[\mathrm{Ar}]$ was varied between about $4 \times 10^{-6}$ and $4 \times 10^{-5} \mathrm{~mol} \mathrm{~cm}^{-3}$ (corresponding to pressures in the range $1-10$ bar).

We illustrate our observations first by Fig. 1 where the formation of $\mathrm{CF}_{2}$ is recorded behind a reflected shock wave at $1328 \mathrm{~K}$. The two spikes are schlieren signals indicating the arrival of the incident and reflected shock waves at the observation window. The formation of $\mathrm{CF}_{2}$ behind the reflected wave follows roughly an exponential time law; however, deviations from this behavior in the initial stage of the reaction are quite obvious. 
In the following we focus on three details of the signals: the final $\mathrm{CF}_{2}$ yields, the time dependence of the $\mathrm{CF}_{2}$ signals at the beginning of the reaction, and the effective rate constants of $\mathrm{CF}_{2}$ formation during the main period of the reaction.

First, we consider the $\mathrm{CF}_{2}$ yields, observed when the signals reach a plateau during our observation time. Doing experiments with reaction mixtures of about 80, 500, and $1000 \mathrm{ppm}$ c- $\mathrm{C}_{4} \mathrm{~F}_{8}$ in $\mathrm{Ar}$, obtained behind incident and reflected shock waves and over the range $1500-$ $2300 \mathrm{~K}$, yields of $Y_{\infty}=\left[C F_{2}\right]_{t=\infty} /\left[c-C_{4} F_{8}\right]_{t=0}=4.0( \pm 0.4)$ were observed. Slightly lower values of $Y_{\infty}$ (near to 3.6) for the lowest reactant concentrations of $80 \mathrm{ppm}$ were most probably due to some loss of reactant by wall adsorption during the preparation of the reaction mixtures before the experiments. The reaction sequence (1) and (3) would correspond to a $\mathrm{CF}_{2}$ yield $Y_{\infty}$ =4.0. As $\mathrm{C}_{3} \mathrm{~F}_{6}$ dissociates much slower than $\mathrm{c}_{-} \mathrm{C}_{4} \mathrm{~F}_{8}$, reaction (2) would lead to $Y_{\infty}=1.0$ (at least this is true as long as the bimolecular reaction (4) does not take place). The yield measurements here clearly indicate that reaction (1) dominates over reaction (2), with $k_{1}$ estimated to be at least 10 times larger than $k_{2}$.

Next, we consider the starting period of the reaction. Fig. 2 shows an example which confirms the conclusions drawn from the yield measurements. The initial slope of $\mathrm{CF}_{2}$ formation is very small; it cannot be distinguished from zero such that no $\mathrm{CF}_{2}$ formation from reaction (2) is detectable. The delayed appearance of $\mathrm{CF}_{2}$ recognized in the figure, on the other hand, can be interpreted by the reaction sequence (1) and (3) with reaction (3) not being fast enough to produce $4 \mathrm{CF}_{2}$ from $\mathrm{c}-\mathrm{C}_{4} \mathrm{~F}_{8}$ instantaneously. The $\mathrm{CF}_{2}$-profile, for a reaction sequence (1) and (3), can be represented in analytical form. Integrating the kinetic equations of reactions (1) and (3) (neglecting reactions (2) and (4)) leads to 
$Y(t)=\left[C F_{2}\right]_{t} /\left[c-C_{4} F_{8}\right]_{t=0}=4\left\{1-\left[k_{3} /\left(k_{3}-k_{1}\right)\right] \exp \left(-k_{1} t\right)+\left[k_{1} /\left(k_{3}-k_{1}\right)\right] \exp \left(-k_{3} t\right)\right\}$

Depending on the ratio $k_{1} / k_{3}$, two regimes are possible. For $k_{1}<<k_{3}$, one has

$Y(t) \approx 4\left[1-\exp \left(-k_{1} t\right)\right]$

whereas, for $k_{1}>k_{3}$, eq. (5) approaches

$Y(t) \approx 4\left[1-\exp \left(-k_{3} t\right)\right]$

Delays in the appearance of $\mathrm{CF}_{2}$ are observed when $k_{1} \approx k_{3}$. At the same time the effective rate constants for the main period of $\mathrm{CF}_{2}$ formation contain contributions from $k_{1}$ and $k_{3}$. The observation of delayed appearances, like those illustrated in Fig. 1 and 2 for experiments in reflected waves, indicates that $k_{1}$ and $k_{3}$ here are of similar magnitude. A further test for the understanding of the kinetics is provided by the comparison of results obtained from incident and reflected waves at similar temperatures. Then the bath gas concentrations [Ar] differ by almost one order of magnitude. While reaction (1) remains in its limiting high pressure range (see below), $k_{3}$ falls off markedly with decreasing pressure ${ }^{3}$. The ratio $k_{1} / k_{3}$ thus increases distinctly by changing from reflected to incident waves, such that the delayed appearances of $\mathrm{CF}_{2}$ disappear and the rate law approaches eq. (8). Fig. 3 illustrates this with a signal recorded 
behind an incident wave. The schlieren signal at the arrival of the incident wave somewhat obscures the absence of the initial stage of the reaction, but the formation of $\mathrm{CF}_{2}$ with the rate law of eq. (8) and the known value of $k_{3}$ is quite definite. As a consequence of this observation, information on $k_{1}$ can only be derived from measurements behind reflected waves, from the evaluation of the initial stage as shown in Fig. 2 and from an analysis of the full $\mathrm{CF}_{2}$ profiles as shown in Fig. 1. Besides evaluating eq. (6) for reactions (1) and (3), we have treated the complete kinetics of reactions (1) - (4) with $\mathrm{k}_{2} \leq 0.1 \mathrm{k}_{1}$ and $\mathrm{k}_{4}$ such as given below. Numerical solution of the kinetic equations showed that the influence of reactions (2) and (4) on $Y(t)$ remained always smaller than the scatter of the signals of Figs. $1-3$.

Extracting $k_{1}$ from the $\mathrm{CF}_{2}$ profiles behind reflected waves under the present conditions meets some difficulties. It cannot be done without using the values of $k_{3}$. A quick estimate of $\tau_{1 / 2}$, i.e. the time when $Y\left(\tau_{1 / 2}\right)=2.0$, is provided by the approximate relationship

$\bar{k} \tau_{1 / 2}=0.765( \pm 0.075)$

which follows from numerical evaluation of eq. (5) where $\bar{k}$ denotes $k_{1} k_{3} /\left(k_{1}+k_{3}\right)$. Eq. (8) bridges the gap between eqs. (6) and (7). While the $\mathrm{CF}_{2}$ yield measurements in the present work are straight-forward, deriving $k_{1}$ is more cumbersome and can only be done in a limited range where $k_{1}$ is of the same order as $k_{3}$. We illustrate the problem in Fig. 4 where $k_{1}$ from Butler $^{6}$ and Simmie et al ${ }^{13}$ is compared with $k_{3}$ (at two different bath gas concentrations) from our earlier work ${ }^{3}$. Modeling the falloff curve of reaction (1) confirmes that this reaction in all previous studies (including the present one) was in its high pressure range. In contrast to 
this, falloff effects in reaction (3) had to be accounted for. Fig. 4, therefore, shows $k_{3}$ for [Ar] $=4 \times 10^{-5} \mathrm{~mol} \mathrm{~cm}^{-3}$ (as employed here in reflected waves) and $4 \times 10^{-6} \mathrm{~mol} \mathrm{~cm}^{-3}$ (as employed here in incident waves). The comparison of $k_{1}$ with $k_{3}$ in Fig. 4 indicates that $k_{3}$ falls below $k_{1}$ with increasing temperature and decreasing pressure. Therefore, $k_{1}$ was here accessible only in experiments with reflected shock waves and low temperatures. Fig. 4 includes the measured points from Simmie et $\mathrm{al}^{13}$ and selected results from the present work. The latter were obtained by evaluating the full $\mathrm{CF}_{2}$ profiles and/or the initial appearance (when only incomplete decomposition was reached within our observation time, which was about $1.5 \mathrm{~ms}$ after which pertubations from the contact surface started to become observable). Because of the necessity to employ also values of $k_{3}$, the present results are estimated to be only accurate to a factor of 2. However, they extend satisfactorily the measurements of Simmie et al ${ }^{13}$ towards higher temperatures. Combining the results of Simmie et $\mathrm{al}^{13}$ and the present work with the low temperature data of Butler ${ }^{6}$, over the range $630-1330 \mathrm{~K}$ leads to

$$
\begin{aligned}
k_{1} & =10^{15.97} \exp \left(-310.5 \mathrm{~kJ} \mathrm{~mol}^{-1} / \mathrm{R} T\right) \mathrm{s}^{-1} \\
& =10^{15.97} \exp (-37340 \mathrm{~K} / T) \mathrm{s}^{-1}
\end{aligned}
$$

The results of the present work differ markedly from the recommendations of Bauer and Javanovic $^{2}$. Here, rate constants $k_{1}=2.10 \times 10^{16} \exp (-37389 \mathrm{~K} / T) \mathrm{s}^{-1}$ and $k_{2}=1.58 \times 10^{17}$ $\exp (-40000 \mathrm{~K} / T) \mathrm{s}^{-1}$ were proposed . This would make $k_{1}$ almost equal to $k_{2}$ at the temperatures of the present study. In addition, $k_{1}$ was predicted to be roughly a factor of 4 larger than the values measured in the present study. The reasons for these discrepancies must be found in the indirect analysis of the reaction mechanism employed by Bauer and Javanovic ${ }^{2}$ under much less simple conditions than those employed here. As the present study observes directly 
the primary dissociation in the absence of a more complicated mechanism of secondary processes, it should lead to more reliable results for $k_{1}$ and to safer conclusions on the magnitude of $k_{2}$.

The question remains how $\mathrm{C}_{3} \mathrm{~F}_{6}$ was formed in earlier work under different conditions. An obvious candidate for $\mathrm{C}_{3} \mathrm{~F}_{6}$ formation is the bimolecular reaction (4) which would not take place at the low reactant concentrations of the present work. With $k_{4} / \mathrm{cm}^{3} \mathrm{~mol}^{-1} \mathrm{~s}^{-1} \approx 2.1 \times 10^{11}$ $\exp (-1263 \mathrm{~K} / T)+6.9 \times 10^{14} \exp (-2134 \mathrm{~K} / T)$ from our earlier work ${ }^{4}$, even at the highest concentrations (1000 ppm in Ar) realized in our work, reaction (4) could always be neglected. This was not the case for the lower $T$ and higher reactant concentrations of earlier experiments.

\section{Quantum-Chemical and Kinetic Modeling of the Primary Dissociation Steps}

In the following section, we try to reconcile our experimental conclusions on reactions (1) and (2) with quantum-chemical calculations of the energetics and structural parameters of their intermediates and transition states. The calculations were performed at the G4MP2 ab initio composite level $^{15}$, using B3LYP/6-31G(2df,p) optimized geometries, harmonic vibrational frequencies (scaled by the factor 0.9854 ) and single-point post-Hartree-Fock ab initio calculations for enthalpies of formation at $0 \mathrm{~K}$. All calculations used the Gaussian 09 software ${ }^{16}$. We note that the G4MP2 enthalpies of formation (at $0 \mathrm{~K}$ ) of singlet $\mathrm{CF}_{2}$ and $\mathrm{C}_{2} \mathrm{~F}_{4}$ were obtained as -198.2 and $-667.8 \mathrm{~kJ} \mathrm{~mol}^{-1}$, being satisfactorily close to tabulated values of $^{17}-191.73$ and $-671.91 \mathrm{~kJ} \mathrm{~mol}^{-1}$, respectively. 
High pressure rate constants $k_{1, \infty}$ and $k_{2, \infty}$ were determined by conventional transition state theory (TST). Low pressure rate constants $k_{1,0}$ and $k_{2,0}$ were calculated using standard unimolecular rate theory ${ }^{18}$ while intermediate falloff curves connecting $k_{0}$ and $k_{\infty}$ were constructed following the simplified procedure of Troe and Ushakov ${ }^{19,20}$.

In agreement with the calculations of Yokoyama et $\mathrm{al}^{14}$ and the discussions by Poutsma ${ }^{1}$ we found that reaction (1) proceeds as a two-step process with intermediate formation of the 1,4biradical $\mathrm{CF}_{2} \mathrm{CF}_{2} \mathrm{CF}_{2} \mathrm{CF}_{2}$, followed by break-up of the central $\mathrm{C}-\mathrm{C}$ bond leading to $2 \mathrm{C}_{2} \mathrm{~F}_{4}$. On the other hand, reaction (2) was found to involve a single transition state only. Fig. 6 shows a sketch of the corresponding energy diagram, whose values, however, somewhat differ from those by Poutsma, constructed on the basis of earlier kinetic and thermochemical information only. $\mathrm{CF}_{2} \mathrm{CF}_{2} \mathrm{CF}_{2} \mathrm{CF}_{2}$ was found to correspond to two loosely bound $\mathrm{C}_{2} \mathrm{~F}_{4}$ molecules separated by a $\mathrm{C}-\mathrm{C}$ bond distance of about $3.7 \AA$ (a triplet $\mathrm{CF}_{2} \mathrm{CF}_{2} \mathrm{CF}_{2} \mathrm{CF}_{2}$ with $\mathrm{C}-\mathrm{C}$ distance of $1.55 \AA$ was also located at $46 \mathrm{~kJ} \mathrm{~mol}^{-1}$ above the singlet ground state). The rate-determining energy barrier of reaction (1) was found to be that for forming $\mathrm{CF}_{2} \mathrm{CF}_{2} \mathrm{CF}_{2} \mathrm{CF}_{2}$ from c$\mathrm{C}_{4} \mathrm{~F}_{8}$ The transition from $\mathrm{CF}_{2} \mathrm{CF}_{2} \mathrm{CF}_{2} \mathrm{CF}_{2}$ to $2 \mathrm{C}_{2} \mathrm{~F}_{4}$ was suggested to occur fast by simple bond scission. The long bond between two $\mathrm{C}_{2} \mathrm{~F}_{4}$ in $\mathrm{CF}_{2} \mathrm{CF}_{2} \mathrm{CF}_{2} \mathrm{CF}_{2}$ is also the reason why reaction (2) does not involve the same biradical intermediate Instaed, it has its own transition state to form $\mathrm{C}_{3} \mathrm{~F}_{6}+\mathrm{CF}_{2}$ The latter according to our calculations at somewhat higher energies than for reaction (1).

Structural parameters required for the calculations of $\mathrm{k}_{1,0}$ and $\mathrm{k}_{1, \infty}$, as calculated here for $\mathrm{c}-$ $\mathrm{C}_{4} \mathrm{~F}_{8}$ and the two transition states, are given in the Appendix. Further parameters calculated are given in the Supplementary Material. Figs. 6 and 7 compare the structures of the two transition states. $k_{1, \infty}$ and $k_{2, \infty}$ can be estimated with the energies, frequencies and rotational constants given in the Appendix. However, there is some ambiguity about how the lowfrequency torsions should be handled. A purely harmonic vibrational model would lead to $k_{1, \infty}$ 
$\approx 6.4 \cdot 10^{14} \exp (-39450 \mathrm{~K} / T) \mathrm{s}^{-1}$ and $k_{2, \infty} \approx 1.7 \cdot 10^{14} \exp (-41920 \mathrm{~K} / T) \mathrm{s}^{-1}$. While this leads to $k_{1, \infty} / k_{2, \infty}>10$ at all temperatures of the present work, being in agreement with the conclusions from our experiments, it differs markedly from the earlier suggestion ${ }^{2}$ of $k_{1, \infty} \approx k_{2, \infty}$. Meanwhile, the calculated $k_{1, \infty}$ are lower than the measured values. Replacing the $90 \mathrm{~cm}^{-1}$ torsion of TS1 by a free rotation (with a reduced moment of inertia of 62 amu $\AA^{2}$ ), could partly cure the problem. One then obtains

$k_{1, \infty} \approx 5.0 \cdot 10^{15} \exp (-38800 \mathrm{~K} / T) \mathrm{s}^{-1}$

which would be only a factor of 2-3 below eq. (9) from the measurements. The disagreement with the values from Bauer and Javanovic ${ }^{2}$ on the other hand is more pronounced, being about a factor of ten. The remaining discrepancy between eqs. (9) and (10) may be due to the general uncertainties in the calculated TS energies from the used quantum-chemical methods. However, changing the two other low-frequency torsions of TS1 into hindered or free internal rotations (see their frequencies in the Appendix) could also raise the preexponential factor of eq. (10) towards the measured value of eq. (9). We did not further explore the barriers for hindered rotations of the three low frequency torsions of TS1. Instead, we conclude that the measured $k_{1}$ is at least semi-quantitatively consistent with the calculations. In addition, $k_{1}>>$ $k_{2}$ is confirmed. We note that the conclusions about the two-step character of reaction (1) is also consistent with the molecular beam study of Yokoyama et $\mathrm{al}^{14}$, measuring the translational energy of the $\mathrm{C}_{2} \mathrm{~F}_{4}$ fragments in the multiphoton dissociation of $\mathrm{c}-\mathrm{C}_{4} \mathrm{~F}_{8}$.

In additon to calculations of $k_{1, \infty}$ and $k_{2, \infty}$ we have also constructed full falloff curves for reactions (1) and (2). We do not elaborate the results here because falloff corrections for both reactions were found to be negligible under all conditions considered. In order to be able to do the corresponding estimates, low pressure rate constants are given in the Appendix. 


\section{Conclusions}

Although the quantitative agreement between measured and calculated $\mathrm{k}_{1}$ is not perfect, several conclusions appear justified. The primary decomposition of $\mathrm{c}-\mathrm{C}_{4} \mathrm{~F}_{8}$ is quite clearly determined by formation of $2 \mathrm{C}_{2} \mathrm{~F}_{4}$ in a two-step process with the 1,4 biradical $\mathrm{CF}_{2} \mathrm{CF}_{2} \mathrm{CF}_{2} \mathrm{CF}_{2}$ as an intermediate. Our calculations indicate that the primary ring opening is rate determining, while the subsequent dissociation of the central bond by a simple bond scission is fast. This differs from the conclusions of Yokoyama et $\mathrm{al}^{14}$ who suggested that the latter process is rate determining. In agreement with their results, we find that the formation of $\mathrm{CF}_{2}+\mathrm{C}_{3} \mathrm{~F}_{6}$ is a single-step process. However, due to its higher energy barrier it contributes only to a very minor extent to $\mathrm{c}-\mathrm{C}_{4} \mathrm{~F}_{8}$ decomposition. Our results suggest that the reaction product $\mathrm{C}_{3} \mathrm{~F}_{6}$ in $\mathrm{c}-\mathrm{C}_{4} \mathrm{~F}_{8}$ decomposition is formed by secondary processes, for instance a reaction of $\mathrm{CF}_{2}$ with $\mathrm{C}_{2} \mathrm{~F}_{4}$ (4).

\section{Appendix Molecular Parameters}

Results from quantum-chemical calculations (see text):

Threshold energies for reactions (1) and (2): $318.4 \mathrm{kJmol}^{-1}$ (TS1) and $341.0 \mathrm{~kJ} \mathrm{~mol}^{-1}$ (TS2), respectively.

Frequencies (in $\mathrm{cm}^{-1}$ ): c- $\mathrm{C}_{4} \mathrm{~F}_{8:}$ 34, 175 (2), 177, 207, 244, 267, 272 (2), 341, 353, 430 (2), 556

(2), 591, 649, 694, 845, 956 (2), 976, 1206 (2), 1233, 1248, 1283, 1314 (2), 1414;

transition state TS1: 147i, 90, 100, 125, 156, 206, 212, 232, 260, 274, 324, 347, 370, 406, $470,519,585,595,622,702,860,950,1038,1069,1141,1176,1313,1343,1390,1477$; 
transition state TS2: 656i, 66, 113, 172, 198, 200, 242, 250, 290, 309, 343, 353, 401, 432 , 519, 571, 598, 637, 656, 682, 784, 870, 1048, 1124, 1171, 1224, 1306, 1346, 1440, 1446.

Rotational constants $\left(\right.$ in $\mathrm{cm}^{-1}$ ): $\mathrm{c}-\mathrm{C}_{4} \mathrm{~F}_{8}: 0.0354$ (2), 0.0288; $\sigma=4 . \mathrm{TS} 1: 0.0414,0.0283$ $0.0237 ; \sigma=1$. TS2: $0.0422,0.0285,0.0271 ; \sigma=1$.

Structures of the transition states TS1 and TS2 illustrated in Figs 7 and 8 Low pressure strong collision rate constants: $k_{1,0} /[\mathrm{Ar}] \mathrm{cm}^{3} \mathrm{~mol}^{-1} \mathrm{~s}^{-1}=4.4 \cdot 10^{12}, 1.0 \cdot 10^{14}, 3.8$ $\cdot 10^{14}$, and $4.9 \cdot 10^{14} ; k_{2,0} /[\mathrm{Ar}] \mathrm{cm}^{3} \mathrm{~mol}^{-1} \mathrm{~s}^{-1}=1.5 \cdot 10^{11}, 9.2 \cdot 10^{13}, 4.2 \cdot 10^{14}$, and $6.0 \cdot 10^{14}$ for $\mathrm{T} / \mathrm{K}=1000,1500,2000$, and 2500, respectively. 


\section{References}

(1) M. L. Poutsma, J. Anal. Pyrol., 92, 25 (2011).

(2) S. H. Bauer and S. Javanovic, Int. J. Chem. Kinet., 30, 171, (1998).

(3) C. J. Cobos, A. E. Croce, K. Luther, L. Sölter. E. Tellbach and J. Troe, J. Phys. Chem. $A, 117,11420(\mathbf{2 0 1 3})$.

(4) C. J. Cobos, L. Sölter, E. Tellbach and J. Troe, J. Phys. Chem. A, 188, 4880 (2014).

(5) C. J. Cobos, L. Sölter, E. Tellbach and J. Troe, J. Phys. Chem. A, 188, 4873 (2014).

(6) J. N. Butler, J. Am. Chem. Soc., 84, 1393 (1962).

(7) B. Atkinson and V.A. Atkinson, J. Chem. Soc., 2086 (1957).

(8) B. Atkinson and A. B. Trenwith, J. Chem. Phys., 20, 754 (1952).

(9) B. Atkinson and A. B. Trenwith, J. Chem. Soc., 2082 (1953).

(10) N. N. Buravtsev, A. S. Grigorev and Yu. A. Kolbanovskii, Kinet. Cat., 26, 7 (1985).

(11) S. H. Bauer, K. C. Hou and E. L. Resler, Phys. Fluids Supp 1, 12, 125 (1969).

(12) A. Lifshitz, H. F. Carroll and S. H. Bauer, J. Chem. Phys., 39, 1661 (1963).

(13) J. M. Simmie, W. J. Quiring and E. Tschuikow-Roux, J. Phys. Chem., 73, 3830 (1969).

(14) A. Yokoyama, K. Yokoyama and G. Fujisawa, Chem. Phys. Lett., 237, 106 (1995).

(15) L. A. Curtiss, P. C. Redfern and K. Raghavachari, J. Chem-Phys., 127, 124105 (2007). 
(16) M. J. Frisch et al, Gaussian 09, Revision A.02 - SMP (Gaussian, Inc., Wallingford, CT, 2009).

(17) E. Goos, A. Burcat and B. Ruscic, Extended Millenium Ideal Gas and Condensed Thermochemical Database for Combustion with Updates from Active Thermochemical Tables (Report ANL 05/20 and TAE 960 Technion-IIT, 2005)

(18) J. Troe, J. Phys.Chem., 83, 114 (1979).

(19) J. Troe, Ber. Bunsenges. Phys. Chem., 87, 161 (1983).

(20) J. Troe and V. G. Ushakov, Z. Phys. Chem, 228, 1 (2014). 


\section{Figure Captions}

Fig. 1 Formation of $\mathrm{CF}_{2}$ from $\mathrm{c}-\mathrm{C}_{2} \mathrm{~F}_{4}$ behind reflected shock wave $\left(\mathrm{CF}_{2}\right.$ absorption at 248 $\mathrm{nm}, \mathrm{T}=1328 \mathrm{~K},[\mathrm{Ar}]=4.2 \cdot 10^{-5} \mathrm{~mol} \mathrm{~cm}{ }^{-3},\left[\mathrm{c}-\mathrm{C}_{4} \mathrm{~F}_{8}\right] /[\mathrm{Ar}]=535 \mathrm{ppm}, \mathrm{OD}=1$ corresponds to $\left.\left[\mathrm{CF}_{2}\right]=3.5 \cdot 10^{-8} \mathrm{~mol} \mathrm{~cm}^{-3}\right)$.

Fig. 2 As Fig. $1\left(\mathrm{~T}=1184 \mathrm{~K},[\mathrm{Ar}]=4.8 \cdot 10^{-5} \mathrm{~mol} \mathrm{~cm}^{-3},\left[\mathrm{c}-\mathrm{C}_{4} \mathrm{~F}_{8}\right] /[\mathrm{Ar}]=1024 \mathrm{ppm}, \mathrm{OD}=1\right.$ corresponds to $\left[\mathrm{CF}_{2}\right]=3.2 \cdot 10^{-8} \mathrm{~mol} \mathrm{~cm}{ }^{-3}$ ).

Fig. 3 Formation of $\mathrm{CF}_{2}$ from $\mathrm{c}-\mathrm{C}_{2} \mathrm{~F}_{4}$ behind incident shock wave $\left(\mathrm{CF}_{2}\right.$ absorption at $248 \mathrm{~nm}$, $\mathrm{T}=1547 \mathrm{~K},[\mathrm{Ar}]=5.4 \cdot 10^{-6} \mathrm{~mol} \mathrm{~cm}^{-3},\left[\mathrm{c}-\mathrm{C}_{4} \mathrm{~F}_{8}\right] /[\mathrm{Ar}]=1024 \mathrm{ppm}, \mathrm{OD}=1$ corresponds to $\left.\left[\mathrm{CF}_{2}\right]=3.8 \cdot 10^{-8} \mathrm{~mol} \mathrm{~cm}^{-3}\right)$.

Fig. 4 Rate constants $k_{1}$ for $\mathrm{c}-\mathrm{C}_{4} \mathrm{~F}_{8}$ decomposition (full line = eq. (9) from this work, refs. 6 and 13; filled symbols $=$ selected experimental results from this work, open symbols $=$ experimental results from ref. 13) and rate constants $\mathrm{k}_{3}$ for $\mathrm{C}_{2} \mathrm{~F}_{4}$ decomposition from ref. 3 $\left(\right.$ dashed line $=k_{3}$ for $[\mathrm{Ar}]=4 \cdot 10^{-5} \mathrm{~mol} \mathrm{~cm}{ }^{-3}$, dotted line $=k_{3}$ for $\left.[\mathrm{Ar}]=4 \cdot 10^{-6} \mathrm{~mol} \mathrm{~cm}{ }^{-3}\right)$.

Fig. 5 Schematic energy diagram for two dissociation possibilities of $\mathrm{c}_{-} \mathrm{C}_{4} \mathrm{~F}_{8}$ (energies in $\mathrm{kJ}$ $\mathrm{mol}^{-1}$ from the present quantum-chemical calculations, see text).

Fig. 6 Quantum-chemically calculated structure of transition state TS1 (see Fig. 5; distances in $10^{-8} \mathrm{~cm}$, angles in degrees).

Fig. 7 Quantum-chemically calculated structure of transition state TS2 (see Fig. 5; distances in $10^{-8} \mathrm{~cm}$, angles in degrees). 


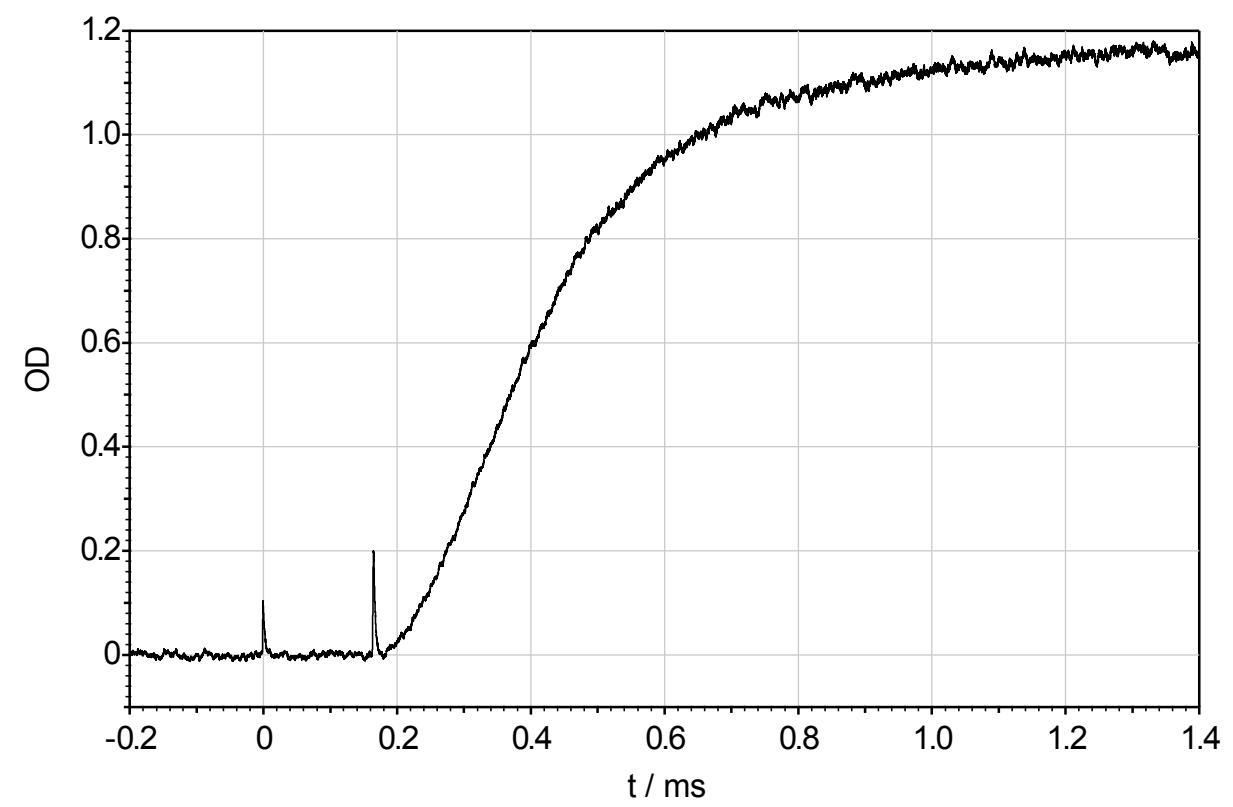

Fig. 1

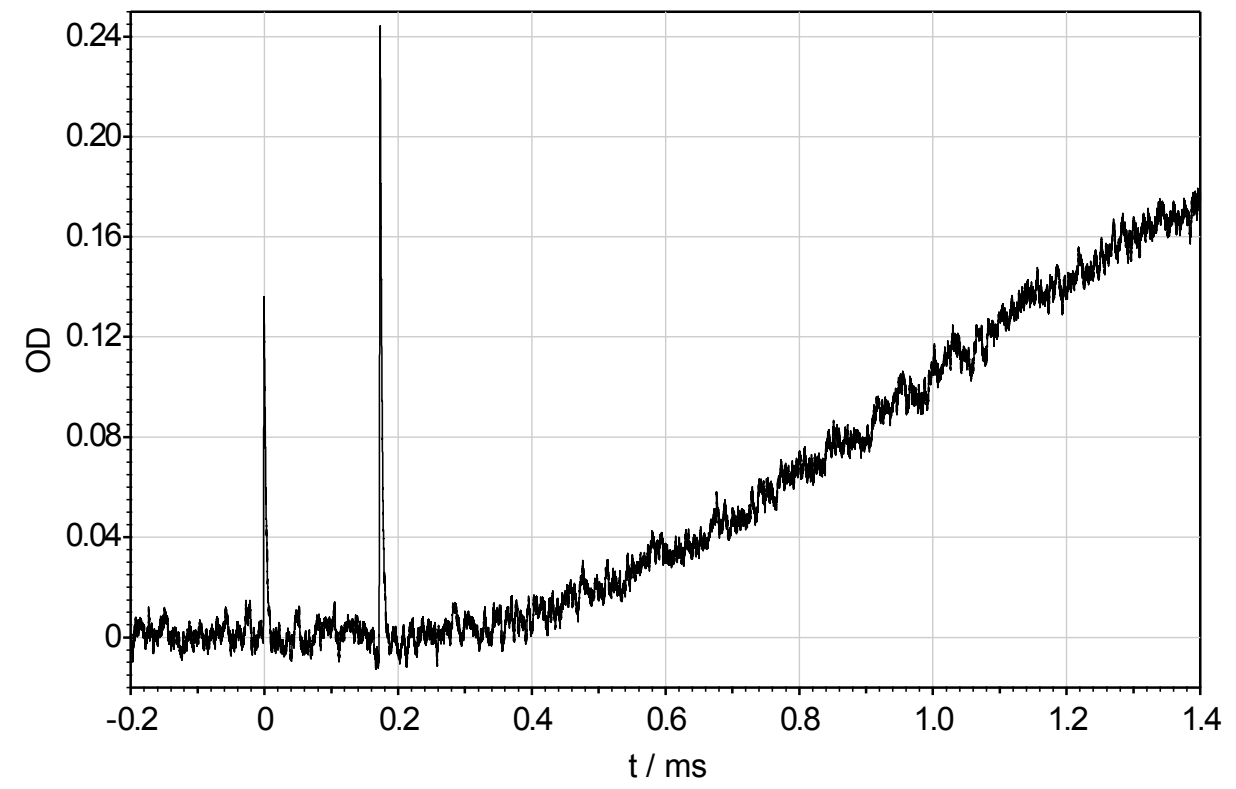

Fig. 2 


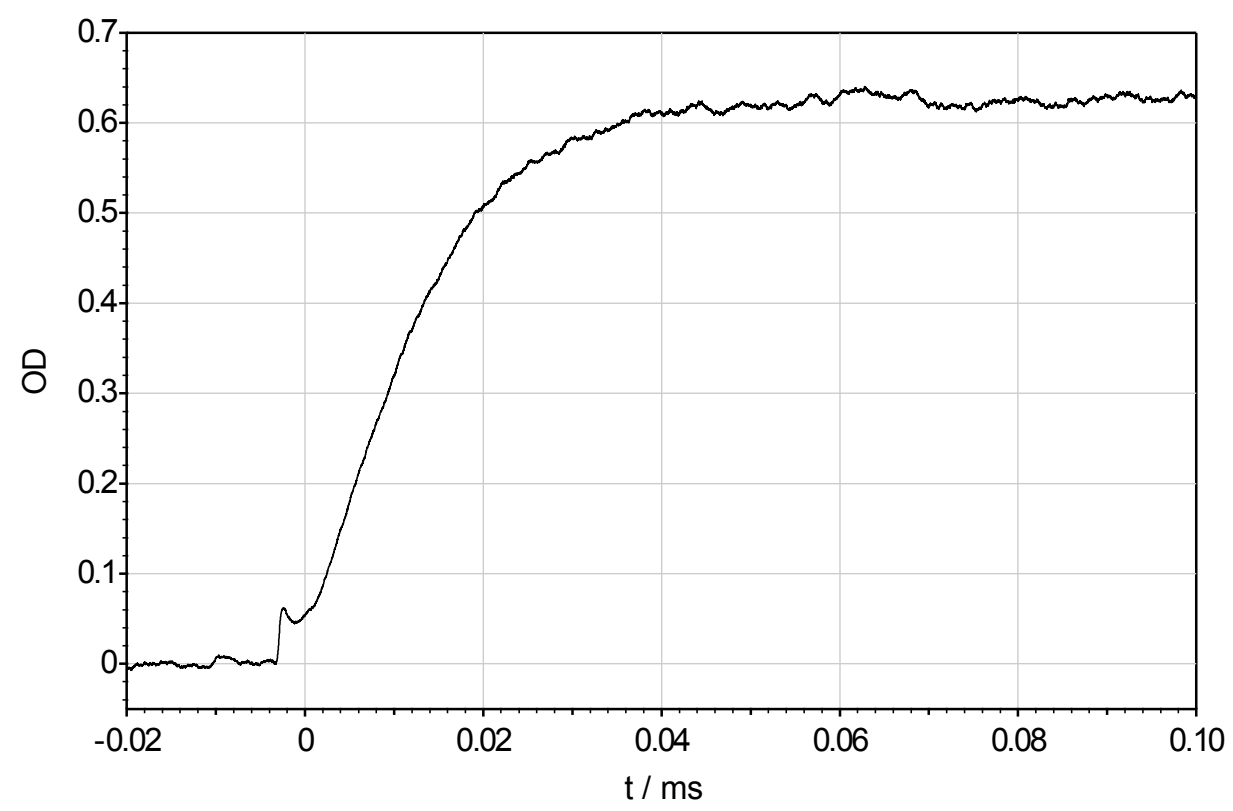

Fig. 3

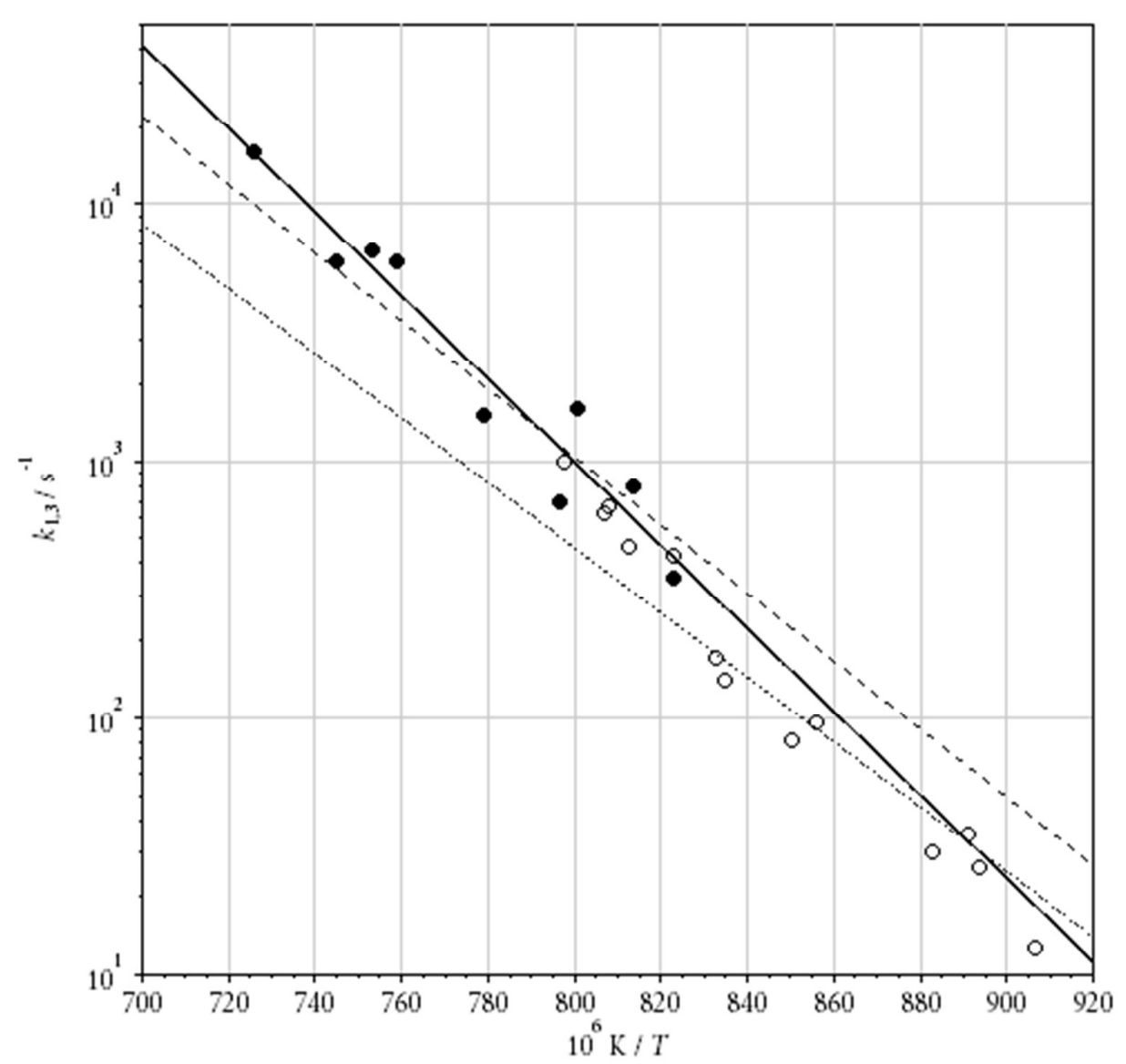

Fig. 4 


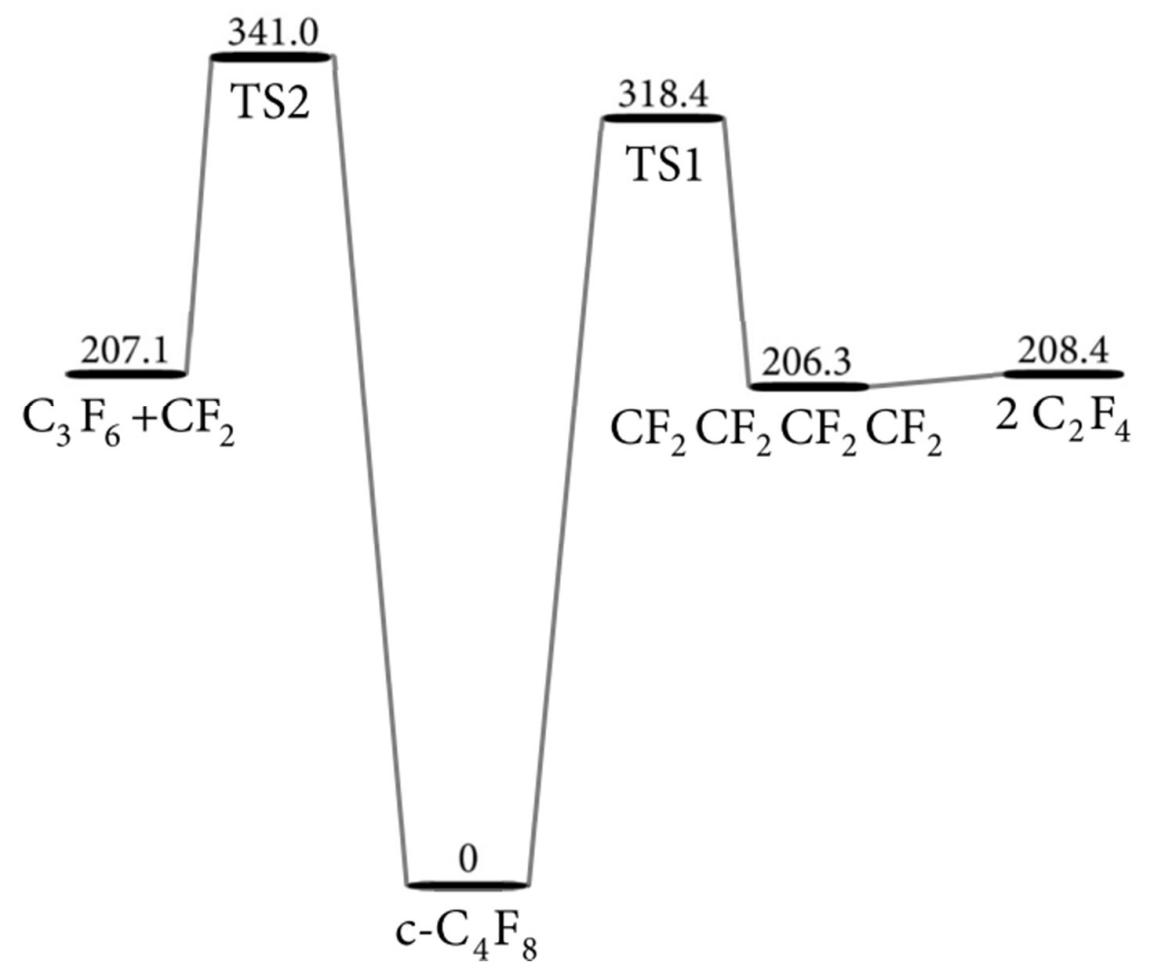

Fig. 5

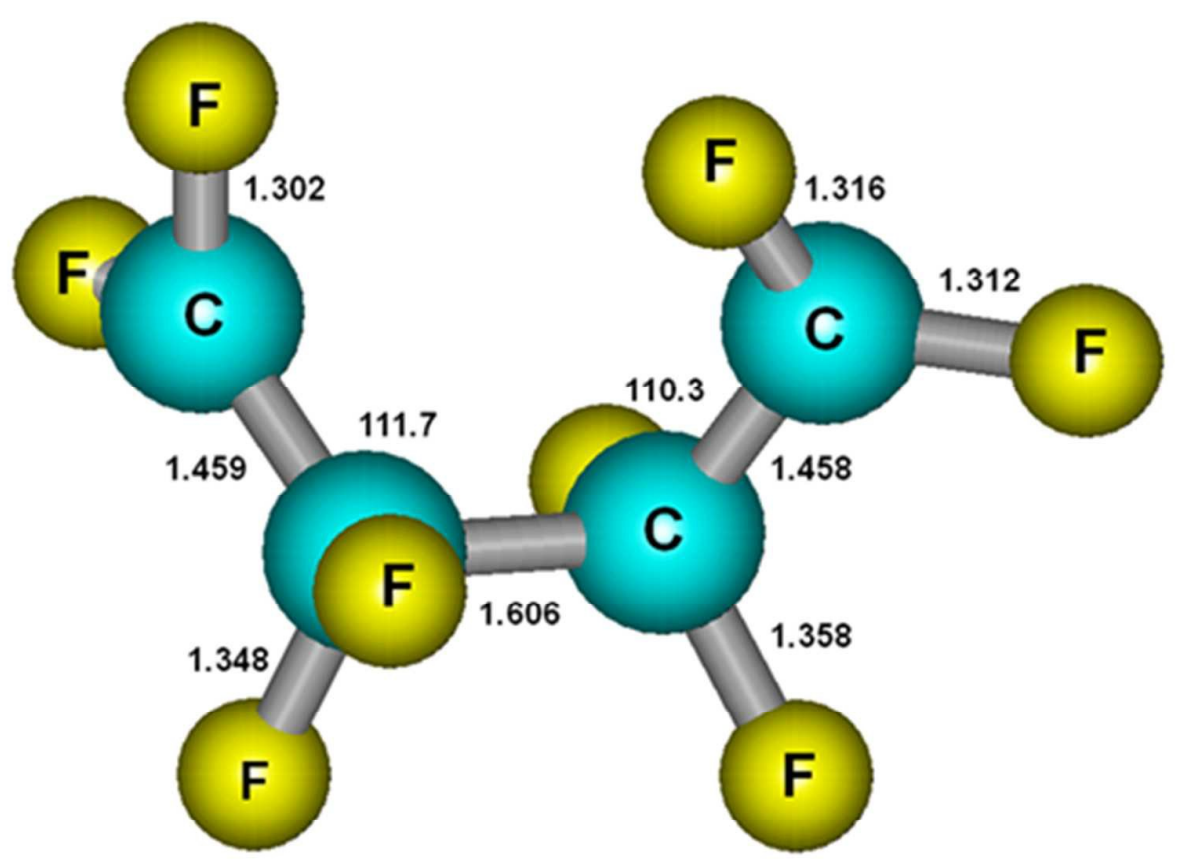

Fig. 6 


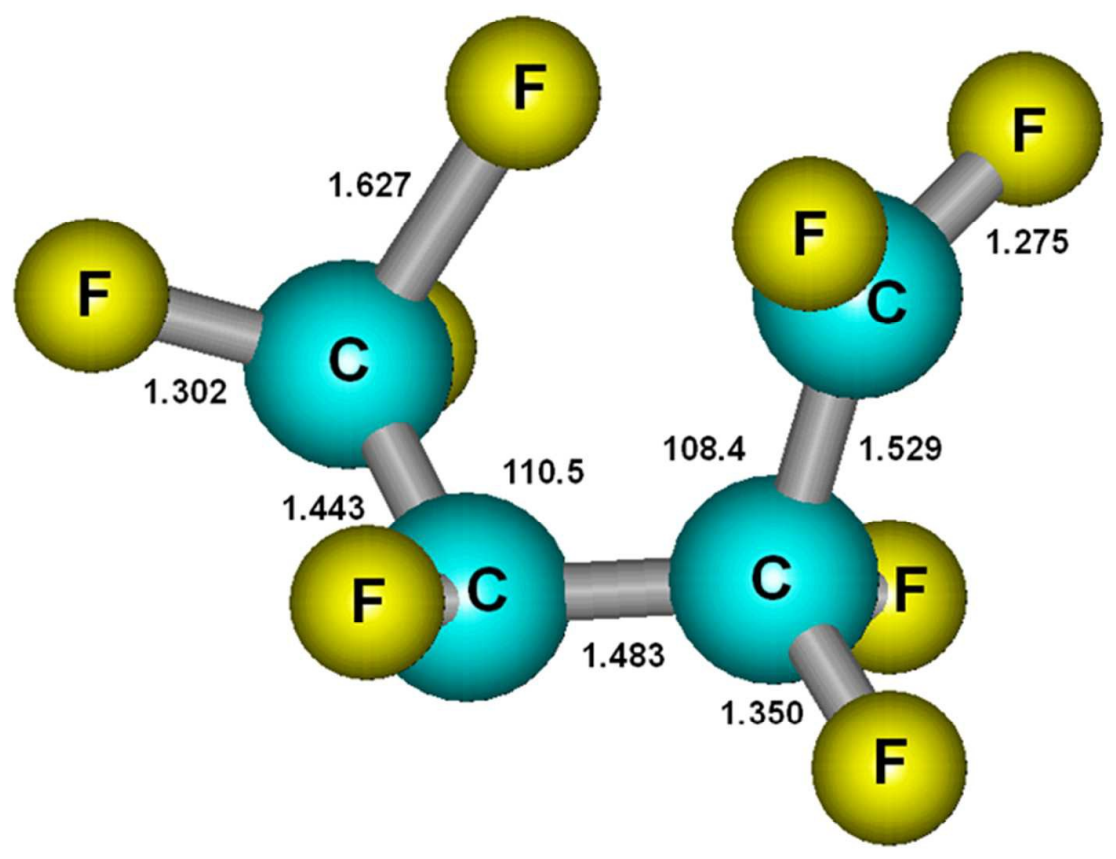

Fig. 7 